\title{
Clubes recreativos: identidades e conflitos entre os trabalhadores paulistanos (1900-1920)
}

\section{Uassyr Siqueira}

Resumo: Este artigo analisa alguns dos clubes recreativos fundados e frequentados pelos trabalhadores da cidade de São Paulo no início do século XX. Oferecendo diversas atividades de lazer para seus associados, propiciavam-lhes uma vida mais coletiva nos momentos de tempo livre. As associações recreativas constituem parte significativa da experiência da classe trabalhadora durante o período, experiência essa marcada pela elaboração de diferentes identidades e por conflitos étnicos. Portanto, são espaços privilegiados para a análise do processo de formação dos trabalhadores da cidade.

Palavras-chaves: trabalhadores, clubes, São Paulo (cidade)

Abstract: This article examines some of the recreational clubs founded and attended by workers of Sao Paulo City in the early twentieth century. This clubs offered numerous leisure activities for its members, allowing for them build a collective life in their moments of free time. These recreational associations represent a significant part of the working class experience during this period, experience marked by the development of different identities and ethnic conflicts. Therefore, these clubs are privileged spaces for the analysis of the working class formation process in the city.

Keywords: workers, clubs, São Paulo City

Desde o final do século XIX, diversas associações voltadas predominantemente para o lazer surgiam na cidade de São Paulo, aumentando significativamente durante o início do século XX. Os clubes recreativos eram algumas das opções de lazer dos trabalhadores paulistanos, propiciando-Ihes "uma vida mais coletiva". ${ }^{1}$ No entanto, embora se caracterizassem como espaços de trabalhadores, que se organizavam em torno do lazer, as associações recreativas ainda são pouco estudadas em suas especificidades. Na maior parte dos estudos, agremiações de auxílio mútuo, sindicatos, grupos libertários e partidos políticos seriam, por excelência, os lugares de organização.

O objetivo deste artigo é analisar alguns dos clubes recreativos que funcionavam nos bairros onde a presença de trabalhadores era marcante, como o Brás, o Bom Retiro e o Bexiga. São associações com finalidades diversas: promotoras de espetáculos teatrais, bailes,

* Doutor em História pela Universidade Estadual de Campinas (2008). Professor da Universidade Metodista de Piracicaba.

${ }^{1}$ DECCA, Maria Auxiliadora Guzzo, A Vida fora das fábricas. Cotidiano operário em São Paulo (1920-1934), São Paulo: Paz e Terra, 1987.

Revista Mundos do Trabalho, vol. 3, n. 5, janeiro-junho de 2011, p. 233-244. 
jogos, etc. Dessa forma, se constituíam enquanto espaços de acesso ao lazer para seus membros, característica essa que faz dos clubes uma parcela significativa da experiência associativa dos trabalhadores paulistanos. Vale ressaltar ainda que algumas sociedades ofereciam acesso à cultura letrada e à informação: possuíam bibliotecas, procurando contribuir para o "progresso moral e intelectual" de seus membros, e mantinham também jornais e revistas para a consulta dos associados.

Em livro de memórias sobre o bairro paulistano do Belenzinho, Jacob Penteado afirma que, nas primeiras décadas do século XX, "eram muito comuns os espetáculos promovidos por amadores do palco, ou melhor, diletantes, como os chamavam então. Havia-os em todos os bairros". ${ }^{2}$ Existiam diversas agremiações de recreio, organizadas pelos trabalhadores, que promoviam apresentações teatrais. Uma das primeiras a ser fundada foi o Grêmio Dramático e Musical Luso-Brasileiro, em 13 de maio de 1900, no bairro do Bom Retiro - onde mantém até hoje a sua sede social. Em seu estatuto, registrado em 1906, definia-se como "sociedade recreativa e beneficente". Tinha como objetivos proporcionar espetáculos e "outras quaisquer diversões lícitas", manter uma biblioteca, criar, "à proporção que os recursos do Grêmio assim o permitirem, aulas diurnas ou noturnas, de música e outras matérias úteis que possam ser aos seus associados". Mantinha ainda um "corpo cênico", composto pelos próprios sócios, e propunha-se também a organizar conferências sobre artes em geral e sobre outros temas que pudessem contribuir para o "progresso moral e intelectual" de seus membros. Já nas disposições gerais de seu estatuto, constava que a sociedade concederia benefícios "aos sócios que os solicitarem, uma vez provada a falta de recursos por moléstias ou desemprego" . ${ }^{3}$ Portanto, lazer, instrução e beneficência se entrelaçavam entre as preocupações da organização, sendo a presença de trabalhadores enfatizada na seguinte notícia, que comentava uma de suas reuniões:

O presidente do Grêmio, Sr. Alfredo Machado, ao assumir a presidência, declarou o fim da reunião. A associação é em geral, disse ele, composta de operários. Estes, com filhos em idade de se educarem, não conseguem matriculá-los nos grupos escolares por falta de lugares. ${ }^{4}$

Naquela ocasião, o presidente honorário do grêmio era o Dr. Celso Garcia, advogado que ganhou notoriedade por sua atuação em prol dos trabalhadores detidos durante a greve da Companhia Paulista, em 1906, e também como vereador da cidade, ao propor um projeto

\footnotetext{
2 PENTEADO, Jacob, Belenzinho, 1910: retrato de uma época. 2ạ Edição São Paulo: Carrenho Editorial/Narrativa Um, 2003.

${ }^{3}$ Arquivo do Estado de São Paulo (doravante AESP), Primeiro Cartório de Registro de Imóveis da Comarca da Capital (doravante PCRICC), Estatuto do Grêmio Dramático e Musical Luso-Brasileiro, 15/1/1907, Sociedade Civil n.o 191, caixa 10.397.

4 “Movimento Associativo", O Estado de S. Paulo, 8/1/1906, p. 2.
} 
de lei que incentivava a construção de casas operárias, em $1907 .{ }^{5}$ Diante das dificuldades, apontadas acima, a associação deliberou oferecer instrução para os filhos dos associados buscando, dessa maneira, suprir um direito ausente da Constituição republicana: a educação primária oferecida pelo Estado. ${ }^{6}$

Outra importante atuação do G. D. M. Luso-Brasileiro deu-se durante a epidemia de Gripe Espanhola, que, em 1918, afetou gravemente os bairros operários: os diretores da agremiação disponibilizaram a sede da associação para o uso da Cruz Vermelha, além da quantia de $100 \$ 000$ mensais enquanto a gripe durasse. Notamos, assim, o peso de sua atuação não somente junto aos seus associados, que tinham a sociedade como um espaço de lazer e de obtenção de auxílios, mas também junto aos moradores do bairro do Bom Retiro, desamparados devido aos parcos recursos médico-hospitalares oferecidos pelo poder público.

Nos primeiros anos do século XX não faltam exemplos de artigos, publicados em diversos jornais operários, que atacavam as organizações recreativas. Os ataques eram feitos por anarquistas e também por adeptos do sindicalismo revolucionário. Os militantes ligados àquelas correntes políticas buscavam, dessa maneira, legitimar o sindicato como o autêntico espaço de organização dos trabalhadores, visto como um local genuíno da organização operária, "onde se conhecem bons camaradas". ${ }^{7}$ Dessa maneira, faziam propaganda contra outras formas de associação. Entre os argumentos utilizados contra os círculos recreativos, constam a "imbecilização" da juventude, o estímulo à libidinagem e o enfraquecimento da consciência de classe.

No entanto, sob a ótica dos dirigentes dos clubes recreativos formados por trabalhadores, as agremiações de recreio tinham outros significados. João de Aguiar, presidente do G. D. M. Luso-Brasileiro em 1918, finalizara da seguinte maneira seu relatório de gestão, em janeiro de 1919:

Saúdo os consócios presentes e faço votos para que eles prestem à nova diretoria que vai ser eleita todo o concurso de sua inteligência e generosidade (...) para que possamos ter orgulho de ver a nossa associação próspera e feliz, trilhando a luminosa [trilha] do progresso, para a glória das classes trabalhadoras, às quais pertencemos. ${ }^{8}$

João de Aguiar era trabalhador ferroviário da Companhia Sorocabana, e possivelmente frequentava outros círculos associativos dos trabalhadores, onde expressava suas concepções políticas a respeito da classe. Em 1908, no jornal A Lucta Proletária, verificamos um artigo assinado por ele, tratando sobre a "Situação Operária": defendia o

\footnotetext{
${ }^{5}$ AMARAL, Pedro Ferraz do, Celso Garcia, São Paulo: Livraria Martins Editora. 1973.

${ }^{6}$ CARVALHO, José Murilo de, Os bestializados. O Rio de Janeiro e a República que não foi. 3a Edição. São Paulo: Companhia da Letras, 1986.

7 “Manifesto dos Tecelões", A Lucta Proletaria, 8/2/1908, pp. 2-3.

${ }^{8}$ Grêmio Dramático e Musical Luso-Brasileiro, Ata de Reunião da Diretoria, 26/10/1918.
} 
"escrúpulo na escolha dos legisladores" como um instrumento de melhoria da situação operária, se posicionando, portanto, em prol da atuação dos trabalhadores nas esferas da política institucional. ${ }^{9} \mathrm{Em}$ seu relatório de gestão, citado acima, Aguiar ressalta a importância da participação dos associados no auxílio da diretoria eleita, enfatizando, assim, o caráter coletivo da responsabilidade pelo bom andamento da agremiação. $\mathrm{O}$ orgulho de ver a associação à qual pertencia próspera e feliz poderia significar a competência dos trabalhadores, classe entre a qual Aguiar se reconhece, e também aos demais membros da associação, em dirigir suas próprias entidades. Na sua visão, trabalhar em prol do G. D. M. Luso-Brasileiro implicava lutas, as quais, sendo bem-sucedidas, levariam ao engrandecimento da entidade, o que contribuiria para o enaltecimento das classes trabalhadoras. Assim, se Aguiar reconhecia a si e aos associados como trabalhadores, podemos dizer também que a luta em prol dos interesses da sociedade era tida, ao menos por esse sócio, como uma luta de trabalhadores em prol de objetivos em comum.

A atuação de João de Aguiar como diretor do G. D. M. Luso-Brasileiro demonstra que a consciência de classe poderia se articular não somente entre os membros das organizações sindicais e políticas - como enfatizavam boa parte das lideranças do movimento operário -, mas também no cotidiano de associações como o G. D. M. Luso-Brasileiro, organização que certamente contribuía para a articulação de uma identidade comum entre seus associados. Isso revela as potencialidades das associações recreativas no processo de formação da identidade de classe.

Outra sociedade recreativa composta por trabalhadores paulistanos foi fundada em dezembro de 1901, sob o título de Sociedade Recreio Artístico. A aprovação de seu estatuto permite perceber as diversas exigências policiais que associações congêneres tinham de cumprir para obter o registro oficial. Encaminhado para a apreciação do Chefe de Polícia do Estado de São Paulo no início de 1902, o estatuto da organização especificava que dela poderiam fazer parte "operários e artistas". No dia 31 de janeiro de 1902 o Dr. Jesuíno Cardoso, Segundo Delegado Auxiliar, emitiu o seguinte parecer ao Chefe de Polícia:

Em obediência ao respeitável despacho retro lançado por V. Excia. na presente petição, venho expender a minha opinião quanto ao requerido: como se vê do art. e, $\S 1$ 1 dos estatutos da sociedade "Recreio Artístico", esta sociedade tem por fins: a) a manutenção de uma banda de música e orquestra para exibições em festas populares e religiosas, mediante prévio contrato revertendo o produto em benefício da caixa da sociedade; b) realizar partidas dançantes e concertos aos seus associados, sempre que o estado financeiro da sociedade o permitir; c) proporcionar aos associados entretenimentos na sede da sociedade, como jogos lícitos e outras diversões, sendo expressamente proibido o jogo a dinheiro, sob pena de serem advertidos e nas suas reincidências suspensos e eliminados. Nestas condições, penso, salvo melhor juízo de V. Excia. que não há motivo para ser

${ }^{9}$ A Lucta Proletária, 8/2/1908, pp. 1-2. 
negada a licença requerida, uma vez que seus fins não contrariam as Leis e regulamentos Policiais. ${ }^{10}$

Os objetivos descritos pelo Segundo Delegado Auxiliar correspondem ao estatuto da associação. A banda musical, além de ser a responsável pela animação das "partidas dançantes", também tinha a função de reverter rendas em benefício da agremiação. As bandas musicais tinham presença marcante nos bairros de trabalhadores, atuando em atividades organizadas por sindicatos, mas também de maneira independente - ocupando um lugar privilegiado entre as "sonoridades que se afirmavam no novo espaço urbano" e com uma tradição cultural bastante diversificada. ${ }^{11}$ Ao afirmar que somente permitiria a realização de "jogos lícitos e outras diversões, sendo expressamente proibido o jogo a dinheiro", a Sociedade Recreio Artístico agiu para facilitar a obtenção do "alvará de licença para que possa funcionar legalmente nessa capital", sujeitando-se às prescrições legais e policiais. A presença desses itens, delimitando o campo de suas atividades diante das exigências legais, era comum nos estatutos de outras sociedades recreativas, como o Éden Clube do Brás, que se registrou em julho de 1909, propondo-se a realizar "toda a sorte de diversões", como leituras de jornais e revistas, jogos de bilhar e "outros considerados lícitos, perante as nossas leis em vigor" ${ }^{12}$ (grifado na fonte)

Analisando a atuação e os objetivos das associações de recreio paulistanas, notamos algumas semelhanças em relação às suas congêneres italianas, como o Circolo di Lettura e Convegno (1896), vinculado à Società di Mutuo Soccorso di Rifredi, da cidade italiana de Firenze - região da Toscana. O referido círculo possuía salão de leituras, sala de jogos e tinha como fim oferecer "agradáveis passatempos aos sócios, com várias recreações lícitas e honestas". ${ }^{13}$

No caso das agremiações paulistanas, a preocupação em funcionar dentro dos limites do legalmente permitido, propondo-se a realizar somente atividades lícitas e regulamentadas pelas leis e decretos referentes aos divertimentos públicos, indica que buscavam, ao menos aos olhos da polícia, desvencilhar-se de práticas condenadas e perseguidas - como os jogos ilegais e os bailes populares que ocorriam em botequins e cortiços da cidade, muitas vezes sem a permissão policial. Buscavam, dessa forma, facilitar a obtenção de alvará para seu funcionamento e uma maior liberdade de atuação diante da fiscalização das autoridades policiais. No entanto, nem todas as agremiações que solicitavam autorização policial sabiam quais jogos de fato eram permitidos. Assim, em março de 1902,

\footnotetext{
${ }^{10}$ AESP, Polícia, Estatuto da Sociedade Recreio Artístico. 14/1/1902, caixa 3.002.

${ }^{11}$ HARDMAN, Francisco Foot, "Lyra da Lapa: acorde imperfeito menor", in PRADO, Antonio Arnoni (Org.), Libertários no Brasil. Memórias, Lutas, Cultura. São Paulo: Brasiliense, 1986.

${ }^{12}$ AESP, PCRICC, Estatuto do Éden Clube do Brás, 22/7/1910, Sociedade Civil n.o 304, caixa 10.405.

${ }^{13}$ TOMASSINI, Luigi, Associazionismo operario a Firenze fra '800 e '900. La società di mutuo soccorso di Rifredi (1883-1922), Firenze: Leo S. Olschki Editore. 1984.
} 
- Segundo Delegado Auxiliar negou a solicitação de licença do Clube $X$, a qual só seria concedida após a retirada de práticas ilegais de seus estatutos, pois a agremiação tinha como objetivos praticar o dominó, o pôquer e outros jogos que não vinham sendo admitidos nas associações paulistanas desde janeiro de $1900 .{ }^{14}$

Com objetivos diversos, oferecendo lazer e atividades de auxílio para os associados, as sociedades recreativas de trabalhadores estabeleciam diversos critérios e exigências para o ingresso em seus quadros sociais. Como princípio mais amplo, destaca-se a admissão de pessoas sem distinção de nacionalidade, mesmo entre as agremiações com acentuada identidade étnica. Exemplifica esse caso o Círculo Recreativo Flor do Brás, fundado em 1908, cujo estatuto foi manuscrito em italiano, o que indica a grande presença de sócios de origem italiana, mas que admitia como sócios "cidadãos de qualquer nacionalidade". ${ }^{15} \mathrm{~A}$ maior parte das associações se dizia composta por "ilimitado número de membros", demonstrando sua intenção de angariar um grande número de sócios.

Quando voltamos a atenção para os critérios de admissão dos associados, notamos uma série de elementos que nos permitem visualizar as sociedades recreativas não somente enquanto promotoras de recreio durante o tempo livre, mas também como espaços que procuravam instituir e afirmar algumas normas sociais para seus membros. Assim, possuir "moralidade de costumes" e "boa conduta", ou ainda, ter "bom procedimento social e não estar envolvido em processo crime" eram requisitos para a admissão no G. D. M. LusoBrasileiro, na Sociedade Recreio Artístico e no Éden Clube do Brás. As sociedades exigiam ainda que os sócios tivessem "ocupação decente e honesta", ou, na versão do estatuto do Éden Clube do Brás de 1919, "ter profissão honesta que lhe assegure meios suficientes para a sua subsistência". ${ }^{16}$ Todos esses critérios, que buscavam estabelecer o perfil dos associados - pautado pela honestidade e pela valorização do trabalho -, são peculiares às agremiações dos trabalhadores e passavam ao largo das exigências que eram feitas por clubes da elite paulistana, como o Clube Atlético Paulistano. Essa associação, cujo presidente em 1915 era Antonio Prado Júnior, filho do ex-prefeito da cidade, Antonio Prado, aceitava como sócios somente "os que, sendo público e notório, gozarem de boa fama na sociedade"17 - uma alusão aos indivíduos de proeminência social e econômica na cidade.

Para garantir a "honestidade" e a decência dos sócios, as sociedades recreativas lançavam mão de dispositivos internos para controlar a admissão de novos membros. $O$ primeiro deles era a exigência de que o ingresso só poderia ocorrer mediante a apresentação por alguém já pertencente à agremiação. O G. D. M. Luso-Brasileiro exigia que o proponente estivesse em dia com as mensalidades, sendo de atribuição da diretoria a aceitação ou não do pedido. O Éden Clube do Brás exigia que as propostas de admissão

\footnotetext{
${ }^{14}$ AESP, Polícia, Secretaria da Justiça e da Segurança Pública, 8/1/1902, caixa 2.987.

${ }^{15}$ AESP, PCRICC, Estatuto do Círculo Recreativo Flor do Brás São Paulo, 2/4/1908. Sociedade Civil n.o 233, caixa 10.399.

${ }^{16}$ Estatuto do Éden Clube do Brás, doc. cit.

${ }^{17}$ AESP, PCRICC, Estatuto do Clube Atlético Paulistano, 4/1/191, Sociedade Civil n. ${ }^{\circ} 470$, caixa 10.417.
} 
viessem acompanhadas do nome do proposto, idade, naturalidade, profissão, estado civil e residência, punindo, com eliminação, os sócios que "propusessem para associado pessoa inadmissível, havendo-se com evidente má fé". ${ }^{18} \mathrm{~A}$ Sociedade Recreio Artístico impunha ainda outra restrição, estabelecendo que os "novos sócios só poderão ser aceitos sob proposta dos sócios fundadores do Recreio Artístico" ${ }^{19}$ Os clubes lançavam mão de outro importante instrumento de controle: as comissões de sindicância, que geralmente eram nomeadas pelas diretorias das agremiações e tinham a função de investigar se as informações apresentadas pelos candidatos a sócios eram verdadeiras, emitindo um parecer para ser enviado à diretoria.

Além dos mecanismos prévios utilizados para fiscalizar a admissão dos sócios, havia também outra forma de controle moral no interior dos clubes recreativos: a atuação dos fiscais de salão. Na Sociedade Recreio Artístico esses membros da diretoria tinham a função de chamar a atenção dos que estivessem transgredindo as normas internas, evitar incidentes nas diversões e "a permanência nos salões da Sociedade de pessoa suspeita ou de má reputação". ${ }^{20}$ Assim, de maneira semelhante aos clubes recreativos dos trabalhadores cariocas, as agremiações possuíam regras de comportamento para "garantir a harmonia em suas atividades". ${ }^{21}$ Esse também era o caso do Circolo di Lettura e Convegno (1896), da cidade italiana de Firenze, que possuía dois chefes de salão para manter a ordem e a harmonia durante a realização de bailes e jogos - com atribuições de expulsar do recinto os eventuais transgressores. Justamente para evitar incidentes, a Sociedade Recreio Artístico também recomendava, nas disposições gerais de seus estatutos: "Nos salões da Sociedade guardarão os srs. Sócios o maior respeito, evitando discussões acaloradas sobre Política e Religião, de modo a não perturbarem o bom funcionamento do Recreio Artístico". 22

As "discussões acaloradas" sobre política e religião eram vistas como causas de possíveis desavenças entre os associados, pois poderiam prejudicar o bom andamento das atividades da associação. No entanto, precavendo-se contra essa possibilidade, os artigos estatutários da agremiação sugerem que os associados, ao mesmo tempo que usufruíam das atividades de recreio, poderiam ter as agremiações como locais onde, no convívio social cotidiano, encontrariam interlocutores para o debate sobre temas diversos, relacionados aos interesses dos diferentes grupos étnicos e nacionais, de diferentes orientações religiosas, que poderiam compor o quadro social das agremiações. No entanto, algumas discussões não se enquadravam nas diretrizes estabelecidas nos estatutos das sociedades. É o que também

\footnotetext{
${ }^{18}$ Estatuto do Éden Clube do Brás. doc. cit.

${ }^{19}$ Estatuto da Sociedade Recreio Artístico. doc. cit.

${ }^{20}$ Idem

${ }^{21}$ PEREIRA, Leonardo Affonso de Miranda, “E o Rio dançou. Identidades e tensões nos clubes recreativos cariocas (1912-1922), in CUNHA, Maria Clementina Pereira (Org.). Carnavais e outras f(r)estas. Ensaios de história social da cultura, Campinas: Editora da Unicamp, Cecult, 2002.

${ }^{22}$ Estatuto da Sociedade Recreio Artístico. doc. cit.
} 
notamos no caso do G. D. M. Luso-Brasileiro, que, além de bailes e apresentações teatrais, tinha como objetivos:

Promover conferências ou preleções sobre assuntos de arte em geral e de tudo quanto possa concorrer para o progresso moral e intelectual dos seus associados, ficando expressamente proibido tratar-se de política ou religião. ${ }^{23}$

Em outras associações proibia-se o tratamento de "assuntos estranhos", como no caso do Círculo Recreativo Flor do Brás São Paulo, fundado em 1908. Debates acalorados, que poderiam girar em torno de política ou religião, eram vistos como fatores de instabilidade para a administração e para a união dos sócios não somente nas associações recreativas. A União dos Canteiros em Pedra Granito do Estado de São Paulo, sindicato fundado em 1909, mencionava que seria "absolutamente proibida qualquer discussão política". ${ }^{24}$ A União dos Operários Metalúrgicos, criada em 1919, afirmava que "não deverá ocupar-se de questões políticas, partidárias ou religiosas". ${ }^{25}$ Para a maior parte das organizações sindicais paulistanas, orientadas principalmente pela corrente do sindicalismo revolucionário, agir politicamente poderia significar a adesão ao anarquismo ou ao socialismo, e também a participação em processos eleitorais por meio de partidos - o que desviaria os trabalhadores das lutas econômicas e da ação direta. Por isso, defendendo que seus membros se identificassem, antes de tudo, como trabalhadores, defendiam a neutralidade política dos sindicatos. A exceção entre os clubes de recreio é o Centro Recreativo da Liberdade, fundado em abril de 1922: além de promover bailes e jogos "permitidos", intentava "fomentar o alistamento eleitoral na Capital" ${ }^{26}$

As associações recreativas paulistanas possuíam objetivos gerais semelhantes voltados não somente para o lazer, mas também para atividades que incluíam a instrução e o auxílio dos associados. No entanto, quando voltamos a atenção para os critérios de admissão dos sócios, notamos que seu funcionamento também era marcado por conflitos étnicos nos bairros paulistanos, como o Cambuci e o Bexiga - ambos de maioria italiana, mas também caracterizados pela presença dos negros.

Como observa Petrônio Domingues, os clubes recreativos da elite paulistana e dos imigrantes não aceitavam negros devido ao racismo, que, arraigado na sociedade paulistana no período pós-abolição, também era a causa de diversos conflitos no cotidiano

\footnotetext{
${ }^{23}$ Estatuto do Grêmio Dramático e Musical Luso-Brasileiro. doc. cit.

${ }^{24}$ AESP, PCRICC, Estatuto da União dos Canteiros em Pedra Granito do Estado de São Paulo, 27/2/1909, Sociedade Civil no. 255, caixa 10.401.

${ }^{25}$ AESP, PCRICC, Estatuto da União dos Operários Metalúrgicos, 21/8/1919, Sociedade Civil n.o 633, caixa 10.428.

${ }^{26}$ AESP, PCICC, Estatuto do Centro Recreativo da Liberdade, 15/4/1922, Sociedade Civil n.o 867, caixa 10.431.
} 
da cidade. ${ }^{27}$ Assim, o Círculo Recreativo Vila Buarque, uma referência ao bairro homônimo, foi fundado em 24 de setembro de 1905, tendo como fim "a recreação, dando ensaios de baile (...) no Largo do Riachuelo, $26^{\prime 28}$, no Bexiga. Essa associação era uma das poucas a mencionar sua sede social nos estatutos registrados no cartório competente. De maneira semelhante aos outros clubes aqui citados, o valor cobrado pela mensalidade era de $3 \$ 000$ e todos os sócios quites tinham o direito de votar e de serem votados para cargos sociais. No entanto, havia as seguintes restrições para associar-se:

\footnotetext{
A Sociedade será internacional e não poderão fazer parte da mesma as pessoas que:

1- sejam de cor;

2 - que não sejam reconhecidos honestos pela [opinião] pública;

3- [que] sejam menores de 16 e maiores de $30 .^{29}$
}

Pelo termo "internacional" o Círculo Recreativo Vila Buarque designava que a ela poderiam se associar pessoas de qualquer nacionalidade, mas, sobretudo, imigrantes e seus descendentes, conforme sugere o nome de seus diretores, de origem italiana: Giuseppe D’Amélio, presidente; Giuseppe Campi, secretário; Paschual Cucio, tesoureiro; Thomazzo Tibério, diretor de sala; Bernardino Jaruzzi, revisor; Miguel Donatelli e Genaro Salerni, primeiro e segundo fiscal, respectivamente. Outras duas associações, que também admitiam pessoas de qualquer nacionalidade, mas que, de acordo com seu nome, demonstram um acentuado contorno italiano, também negavam o ingresso de pessoas "de cor": o Círculo Dramático e Recreativo Città di Roma (1920), com sede na Rua do Lavapés, no bairro do Cambuci $^{30}$, e o Círculo Filodramático e Recreativo Roma (1921), sediado na Rua Oriente, no Brás $^{31}$. Ambas as associações exigiam que os sócios exercessem profissões honestas. Dessa forma, construíam concepções de trabalho, e de trabalhador, que excluíam indivíduos negros, pois, mesmo podendo se ocupar de profissões vistas como honestas, não poderiam ser admitidos nas referidas agremiações. Assim, observamos um processo bastante semelhante ao apontado por David R. Roediger para o caso da classe trabalhadora nos

\footnotetext{
${ }^{27}$ DOMINGUES, Petrônio, Uma história não contada. Negro, racismo e branqueamento em São Paulo pósabolição, São Paulo: Editora Senac, 2004, p. 173.

${ }^{28}$ AESP, PCRICC, Círculo Recreativo Vila Buarque, 9/8/1906. Sociedade Civil n. ${ }^{\circ} 182$, caixa 10.396.

${ }^{29}$ Idem.

${ }^{30}$ AESP, PCRICC, Estatuto do Círculo Dramático e Recreativo Città di Roma, 3/3/1920, Sociedade Civil n. ${ }^{\circ} 695$, caixa 10.431.

${ }^{31}$ AESP, PCRICC, Estatuto do Círculo Dramático e Recreativo Roma, 15/3/1921, Sociedade Civil n. ${ }^{\circ} 777$, caixa 10.435. Na versão modificada de seus estatutos, em 1928, a agremiação retirou o critério de "cor" como item de restrição ao ingresso dos sócios.
} 
Estados Unidos, onde, em diversas ocasiões, trabalhadores brancos formavam sua identidade se afirmando superiores ou atribuindo características depreciativas aos negros. ${ }^{32}$

Em um caso bastante ilustrativo das relações entre imigrantes e negros nas associações recreativas, percebemos que os conflitos étnicos e as divergências entre trabalhadores imigrantes e trabalhadores nacionais estavam intimamente relacionados. 0 ocorrido se inicia quando, no dia 22 de outubro de 1908, em resposta ao pedido feito por Luiz Assumpção Scatena, secretário da agremiação, foi emitido parecer favorável à aprovação do estatuto do Grêmio Dramático e Recreativo 18 de Agosto, localizado no Distrito de Santa Ifigênia. Uma primeira solicitação havia sido indeferida, pois o requisitante, João Alves Ferreira, presidente da associação, não havia mencionado o endereço da sede social do grêmio. Suas finalidades eram "promover festas recreativas, como bailes, piqueniques, representações teatrais e outros divertimentos lícitos em que os sócios possam tomar parte com os respectivos familiares". Foi definido que poderiam fazer parte do grêmio "todos os operários e artistas da cidade de São Paulo, de honestidade reconhecida e sem distinção". ${ }^{33}$

Já no dia 27 de outubro de 1908, apenas cinco dias após a validação do estatuto do G. D. R. 18 de Agosto, a polícia recebeu uma nova solicitação para a aprovação de um novo estatuto da agremiação. O requerente alegava que o regulamento anterior não havia sido anuído pela diretoria eleita em 18 de agosto de 1908, e que teria sido enviado para aprovação por diretores não mais em exercício, nem sequer mais pertencentes ao quadro de sócios, por falta de pagamento das mensalidades. Assim, o novo estatuto especificava que "poderão ser admitidos a tomar parte do Grêmio pessoas de qualquer profissão, porém nacionais". Ou seja, a associação não mais admitia trabalhadores imigrantes em seu quadro de associados. ${ }^{34}$ (grifos meus)

Como observa Michael Hall, apesar das semelhanças culturais entre os imigrantes italianos e a população brasileira, conflitos de proporções consideráveis ocorreram entre os dois grupos. Em 1896, um grupo de nativistas invadiu o teatro São José durante uma apresentação em benefício do Hospital Italiano, aos gritos de "Morte à Itália", ou ainda, "Viva Menelik", uma referência ao líder que recentemente havia derrotado os invasores italianos na Etiópia. Essas hostilidades adviriam dos ressentimentos dos brasileiros na competição por empregos, da revolta diante da grande presença de italianos na cidade, do racismo e da "manobra da alta política brasileira". ${ }^{35}$ George Andrews, por sua vez, revela também o preconceito das próprias lideranças sindicais contra trabalhadores negros: apesar

\footnotetext{
${ }^{32}$ ROEDIGER, David R. Towards the abolition of whiteness. Essays on Race, Politics, and Working Class History. London - New York: Verso. 1994.

${ }^{33}$ AESP, Polícia, Secretaria de Justiça e Segurança Pública. 24/10/1908, caixa 3.163.

${ }^{34}$ AESP, Polícia, Secretaria da Justiça e da Segurança Pública, Estatuto do Grêmio Dramático e Recreativo 18 de Agosto, 27/10/1908, caixa 3.163.

${ }^{35}$ HALL, Michael, "Imigrantes na cidade de São Paulo", in PORTA, Paula. História da Cidade de São Paulo. A cidade na primeira metade do século XX. São Paulo: Paz e Terra, 2004.
} 
de seus apelos pela igualdade racial e pela solidariedade da classe trabalhadora, "muitos líderes operários imigrantes não conseguiam superar completamente os sentimentos de superioridade étnica e racial em relação a seus companheiros brasileiros" ${ }^{36}$

O mais provável é que a mudança dos critérios de admissão de sócios no G. D. R. 18 de Agosto tenha ocorrido devido aos conflitos entre imigrantes e negros que compunham a agremiação. Entre os membros da diretoria mencionados no novo estatuto para aprovação, não consta nenhum com sobrenome de origem italiana, como Luiz Assumpção Scatena, secretário da primeira gestão. Além disso, possivelmente diante da recusa da polícia em aceitar as modificações estatutárias propostas em 27 de outubro de 1908, a maior parte dos diretores e sócios que endossaram o pedido daquelas alterações fundou o Grêmio Dramático e Recreativo Kósmos, em 15 de novembro do mesmo ano. Essa agremiação também admitia "pessoas de qualquer profissão, porém nacionais", e, como ressalta Petrônio Domingues, foi uma das associações negras de maior destaque até a década de 1930, dado o seu "alto grau de organização e capacidade de penetração na comunidade negra". ${ }^{37}$ Bastante sugestiva foi a data escolhida para sua fundação: o dia comemorativo da Proclamação da República, fazendo com que a intenção de admitir somente trabalhadores nacionais fosse ao encontro das idealizações mais amplas em torno da exaltação da nação. Apesar dos conflitos existentes entre italianos e negros, as fronteiras culturais entre ambas as categorias étnicas não devem ser vistas como imutáveis: a experiência da organização do G. D. R. 18 de Agosto revela que, apesar do racismo, poderiam conviver numa mesma organização, compartilhando interesses em comum, ligados à prática do lazer. As desavenças podem ser explicadas pelas hostilidades entre trabalhadores nacionais e trabalhadores imigrantes, mas também por conflitos mais específicos: cobrança de mensalidades atrasadas, maneiras de gerir a associação, tipos de eventos que deveriam ser realizados prioritariamente, e outros. Assim, como observaram Philippe Putignat e Jocelyne Streiff-Fenart:

a etnicidade não se define como uma qualidade ou uma propriedade ligada de maneira inerente a um determinado tipo de indivíduos ou de grupos, mas como uma forma de organização ou um princípio de divisão do mundo social cuja importância deve variar de acordo com as épocas e situações. ${ }^{38}$

\footnotetext{
${ }^{36}$ ANDREWS, George Reid, Negros e Brancos em São Paulo (1888-1988), São Paulo: Edusc, 1998, p. 108.

${ }^{37}$ DOMINGUES, Petrônio, op. cit, p. 331. Sobre o Estatuto do G. R. D. Kósmos ver: AESP, Polícia, Secretaria da Justiça e da Segurança Pública, Estatuto do Grêmio Recreativo e Dramático Kósmos, 5/12/1908, caixa 3.163.

${ }^{38}$ POUTIGNAT, Philippee STRIFF-FENART, Jocelyne, Teorias da Etnicidade. Seguido de grupos étnicos e suas fronteiras de Fredrik Barth. São Paulo: Fundação Editora da Unesp, 1998. Tradução: Élcio Fernandes, pp. 124125.
} 
As relações étnicas tornam-se ainda mais complexas quando levamos em conta que os grupos não se constituíam como categorias homogêneas, imunes aos conflitos internos. Como observou Luigi Biondi, entre 1878 e 1918 as sociedades mutualistas italianas, embora se declarassem apolíticas, se dividiam entre favoráveis e contrárias ao governo italiano - divergência que se refletia nas comunidades italianas. ${ }^{39}$ As desavenças também ocorriam em termos religiosos: em livro de memórias, Armadinho do Bexiga ressalta a grande rivalidade entre os devotos de Nossa Senhora da Achiropita, padroeira da cidade de Rossano, na Calábria, e os devotos de Nossa Senhora Ripalta, padroeira da cidade de Cerignola, na Baixa Itália. ${ }^{40}$

As associações recreativas paulistanas, portanto, devem ser vistas como uma das possibilidades que trabalhadores, de diferentes grupos étnicos, tinham para obter diferentes recursos necessários ao seu cotidiano. Não somente atrás de diversão iam seus associados, mas também à procura dos diferentes recursos que as organizações poderiam lhes oferecer, como auxílios em caso de doença ou de desemprego, atividades de instrução e de educação, etc. Dessa maneira, consistiam em espaços que faziam parte do leque de associações disponíveis, e com grande potencial para dar conta de diversas demandas dos que ingressavam em seu quadro de associados. São, portanto, espaços privilegiados para a análise do processo de formação da classe trabalhadora, processo esse marcado por conflitos, mas também pela formação de identidades em comum.

Recebido em 14/03/2011

Aceito para publicação em 31/07/2011

\footnotetext{
${ }^{39}$ BIONDI, Luigi, Entre associações étnicas e de classe: os processos de organização política e sindical dos trabalhadores italianos na cidade de São Paulo (1890-1920), Tese de Doutorado, Campinas: IFCH/UNICAMP, 2002, p.166.

${ }^{40}$ MORENO, Júlio, Memórias do Armadinho do Bixiga, São Paulo: Editora Senac, 1996, p. 73.
} 